\title{
Intersetorialidade e cuidado em saúde mental: experiências dos CAPSij da Regiáo Sudeste do Brasil
}

| ${ }^{1}$ Bruna Lidia Tãno, ${ }^{2}$ Thelma Simões Matsukura |

Resumo: O objetivo do estudo foi identificar como tem sido produzido o trabalho intersetorial nos Centros de Atenção Psicossocial Infantojuvenis (CAPSij) da Região Sudeste do país, buscando compreender como se processam os contatos com a rede, bem como as potências e fragilidades das articulaçôes intersetoriais na perspectiva dos gestores dos serviços. Trata-se de pesquisa de levantamento, orientada pela avaliação por triangulação de métodos, em sua primeira etapa referente à análise diagnóstica situacional, tendo como participantes 35 CAPSij. Os resultados indicaram que Atenção Básica, Assistência Social e Educação são os principais serviços/setores envolvidos nas situaçóes de cuidado à população infantojuvenil acompanhada nos CAPSij. A corresponsabilização, enquanto um dos benefícios do trabalho intersetorial, foi afirmada como estratégia para a produção ampliada de saúde e qualificação da rede. Sobre desafios, os participantes apontam a falta de alinhamento em projetos comuns de cuidado, os discursos de medicalizaçáo e patologização da vida nas instituiçóes educacionais, e a dificuldade de articulação das demandas relacionadas à Atenção Básica. Por fim, discute-se a intersetorialidade como eixo central das ações em saúde mental, possibilitando que recursos e dispositivos locais sejam potencializados para práticas de cuidado e de garantia de direitos.

> Palavras-chave: saúde mental; criança; adolescente; intersetorialidade.

\footnotetext{
1 Departamento de Terapia Ocupacional, Universidade Federal do Espírito Santo. Vitória-ES, Brasil (brunatano@gmail.com). ORCID: 0000-0002-0101-4100.

2 Programa de Pós-Graduação em Terapia Ocupacional, Universidade Federal de São Carlos. São CarlosSP, Brasil (thelmamatsukura@ gmail.com). ORCID: 0000-0003-3812-3893.
}

Recebido em: 09/03/2018 Revisado em: 15/12/2018 Aprovado em: 21/12/2018 


\section{Introdução}

Historicamente, as açóes direcionadas para crianças e adolescentes em sofrimento psíquico estiveram sustentadas em práticas filantrópicas, de caráter reparador, especialmente centradas na descrição e compreensão dos fenômenos pela chave de leitura da deficiência mental. Psiquiatria, educaçáo e psicologia pouco se ocuparam das crianças e adolescentes em situaçóes de intenso sofrimento psíquico, embora a prevenção das doenças mentais figurasse como o principal objetivo descrito. Ainda que o campo tenha se conformado com diferentes disciplinas e saberes, a fragmentação das condutas e a individualização das intervençôes foram os movimentos correntes na constituição da assistência para estes sujeitos, pouco considerados nas políticas públicas deste país até início do século XXI (COUTO; DELGADO, 2016; TAÑO; MATSUKURA, 2015).

Somente no início da década de 2000, por meio da Portaria 366/2002, que se efetiva em plano nacional a criação de dispositivos de cuidado para a população de crianças e adolescentes em trajetória de sofrimento psíquico, os Centros de Atenção Psicossocial Infantojuvenis (CAPSij). Os CAPSij ${ }^{1}$ são serviços de saúde destinados a crianças e adolescentes que apresentam graves comprometimentos emocionais e psíquicos, como também consequências provenientes do uso de álcool e outras drogas e/ou situaçóes de importante vulnerabilidade psicossocial, devendo estar localizados em municípios com mais de 70 mil habitantes (BRASIL, 2011).

Com a promulgação da Portaria 3.088, de 23 de dezembro de 2011, que institui a Rede de Atenção Psicossocial (RAPS), enquanto marco orientador e propositivo de ampliações na atenção em saúde mental atrelado às mudanças já assinaladas pela Lei 10.216 de 2001, pretende-se que a atenção em saúde mental funcione de modo articulado em diferentes pontos de atenção (serviços). Nesta direção, afirma-se, no campo do planejamento em saúde, que a atenção em saúde mental representa mais que apenas o acompanhamento dos sujeitos pelos serviços especializados/estratégicos. Tal perspectiva reconhece, portanto, que a melhor atenção em saúde mental é aquela que possibilita que os sujeitos possam articular suas vidas com cidadania e participação social, a partir de suas redes, de seu território e dos dispositivos de cuidado lá estabelecidos (BRASIL, 2011).

Especificamente para a atenção às crianças e adolescentes em sofrimento psíquico, a Rede de Atenção Psicossocial ganha novo contorno com a possibilidade 
de agenciamento de outros pontos de atenção que não somente os CAPSij, bem como é fortalecida a relevância da Atenção Básica na gestão do cuidado e na defesa de açôes que de fato estejam presentes nos territórios e comunidades por meio da gestão das redes e dos acordos e açôes intersetoriais (BRASIL, 2011; 2014).

No Brasil, a Política Nacional de Promoção da Saúde - PNPS - (BRASIL, 2006; 2015) é considerada a primeira normativa oficial a indicar a intersetorialidade como estratégia para a produção e promoção de saúde. Indica a necessidade de envolvimento dos trabalhadores, usuários e territórios na produção de subjetividades mais solidárias, corresponsáveis e participativas, por meio da mobilização de recursos humanos, financeiros, territoriais e políticos, para a garantia da saúde e da cidadania como direitos humanos.

Em termos objetivos, compreende-se que a intersetorialidade se afirma em práticas contextualizadas, sendo apoiada por diferentes atores sociais e relativa a problemas reais e, portanto, somente por meio destes pode ser empreendida. O conhecimento e o saber articulados são produzidos em arenas dialógicas, entendidas enquanto espaços de diálogo e elaboração de alternativas para as problemáticas elencadas a partir dos diferentes sujeitos envolvidos, nos quais distintos interesses, perspectivas e valores são colocados em jogo (MENDES; AKERMAN, 2007). Logo, o compromisso concreto a ser assumido, nesta proposição, pelas equipes de saúde, de outras políticas sociais e das comunidades traduz-se no exercício cotidiano da corresponsabilização pelo cuidado, pela construção de projetos de vida, e pela garantia dos direitos (BRASIL, 2014; 2014b).

A corresponsabilização contribui, assim, para o aumento da participação comum, na superação de disputas de poder, dando lugar para relaçóes mais transversalizadas que possam oferecer chances para a produção de reflexões, articulaçôes e estratégias coletivamente pensadas. E, nesse sentido, pode inclusive se situar como dinâmica e operador importante nas açôes entre setores, políticas e programas sociais que buscam fundar suas estratégias na promoção da cidadania, intersetorialidade e participação popular mais autônoma dos envolvidos nas problemáticas (BRASIL, 2008; CARMO; GUIZARDI, 2017; GELINSKI, 2011).

Todavia, ainda que as políticas e normativas, em especial as de saúde mental, apresentem as necessidades de adequação e transformação das lógicas de cuidado, na perspectiva da intersetorialidade e do trabalho em rede, é importante marcar que esta não se expressa em sua integralidade na realidade brasileira, sendo ainda um desafio 
relevante para as crianças e adolescentes (DUARTE et al., 2010; DELGADO, 2015a; 2015b; ZANIANI; LUZIO, 2014).

Em estudo que objetivou caracterizar a rede pública ampliada em saúde mental para infância e adolescência em quatro regiôes do Estado do Rio de Janeiro, em relação às instituiçôes de diferentes setores (justiça/direitos; assistência social; educação e saúde), Duarte e colaboradores (2010) identificaram a importância de que as questôes de saúde mental possam ser expandidas para outros serviços que não somente os especializados, evidenciando que estes reconhecem exercer práticas ligadas ao tema. Os autores apontam para a relevância da construção de outros estudos que possam abranger o aprofundamento da realidade dos sistemas de atenção existentes de modo mais qualitativo.

Em estudo de revisão, Zaniani e Luzio (2014), a respeito de publicações sobre as açôes intersetoriais realizadas pelos CAPSij entre os anos de 2001 e 2011, identificaram que a intersetorialidade não constava como perspectiva de análise em relação aos resultados apresentados em cada um dos estudos. Nesse sentido, outras definiçôes ou conceituaçôes sobre o termo foram pouco exploradas. As autoras discutem que, ainda que a intersetorialidade seja proposta enquanto ação dos serviços em relação ao cuidado imediato das crianças e adolescentes, esta não é debatida em seus fundamentos e tampouco elaborada em relação às formas de análise com que se situam nas produçôes, e ainda não exploram os modos com que se constituem as açôes intersetoriais e a efetivação das redes.

Considerando a trajetória histórica de violação dos direitos das crianças e adolescentes em território nacional, como já assinalado, e a necessidade de reordenação das práticas que possam de fato garantir direitos, o trabalho na perspectiva da construção de redes e, tão logo da intersetorialidade, se situa enquanto um posicionamento metodológico e ético, central para a atenção psicossocial, na qual os CAPSij desempenham papel fundamental. O exercício da intersetorialidade, enquanto prática central nos serviços para saúde mental, possibilita que a singularidade das estratégias para o cuidado de crianças e adolescentes seja pauta frequente, além de servir como método para a gestão, planejamento, monitoramento e avaliação das condutas e açôes realizadas (BRASIL, 2014; COUTO; DELGADO, 2010; 2015b).

Pelo exposto, compreende-se a necessidade de se produzirem estudos que tratem da construção da intersetorialidade na Atenção Psicossocial a crianças e adolescentes, de modo que possam apoiar a consolidação das práticas e a elaboração de outras 
estratégias de cuidado e participação, uma vez que é a articulação intersetorial preconizada como principal estratégia para um cuidado potente (OMS, 2005). Tal como também aponta Delgado (2015a; 2015b), a produção científica sobre as açôes intersetoriais na Atenção Psicossocial se situa como relevante recurso para o fortalecimento e defesa das práticas realizadas.

Assim, o estudo ora apresentado objetivou identificar como tem sido produzido o trabalho intersetorial nos Centros de Atenção Psicossocial Infantojuvenis (CAPSij) da Região Sudeste do país. Buscou também compreender como se processam os contatos com a rede, bem como as potências e fragilidades das articulaçóes intersetoriais na perspectiva dos gestores dos serviços.

\section{Método}

Trata-se de pesquisa exploratória e de levantamento, atrelada à investigação mais ampla, que se orientou pela avaliação por triangulação de métodos (MINAYO; ASSIS; SOUZA, 2005). ${ }^{2}$ Estudos desta modalidade buscam evidenciar por meio da ação coletiva os sentidos éticos, os valores técnicos e o compromisso social das práticas realizadas por diferentes grupos e/ou instituiçôes, especialmente relacionados a programas/projetos sociais. No geral, congregam as abordagens quali e quantitativas, na tarefa da elucidação/reorientação de estratégias em programas, projetos e serviços de modo que sua eficiência, ética e eficácia possam ser potencializadas. Nessa modalidade participativa de produção de conhecimento, os limites, potenciais e alcances dos projetos são colocados em análise, conjuntamente entre pesquisadores e atores sociais implicados. Os resultados apresentados nesta oportunidade referem-se à etapa de análise diagnóstica situacional, que teve como enfoque principal a identificação e a discussão acerca da expansão e magnitude das açôes intersetoriais destacadas. Quanto aos aspectos éticos, obteve aprovação inicial do Comitê de Ética em Pesquisa em Seres Humanos da Universidade Federal de São Carlos, com número de parecer 748.766.

Este estudo foi desenvolvido junto a 35 CAPSij, da Regiáo Sudeste do Brasil, sendo 1 no Espírito Santo, 3 em Minas Gerais, 5 no Rio de Janeiro e 26 em São Paulo, representados cada um pelos seus gestores locais/coordenadores e/ou técnicos indicados por estes. Para o Estado de Sáo Paulo, a participação de CAPSij que compuseram a amostra deste estudo representou $45 \%$ da totalidade dos serviços 
habilitados no estado; no Estado do Rio de Janeiro, correspondeu a 21\% do total de serviços; em Minas Gerais, foi de 16\%; e, no Espírito Santo, representou 100\%. A escolha pelo recorte da Regiáo Sudeste decorreu do fato de que esta é a região com a maior porcentagem de CAPSij habilitados do Brasil, concentrando mais de 50\% destes equipamentos disponíveis no país (BRASIL, 2015).

O instrumento utilizado consistiu em questionário, respondido pelos gestores, autoaplicável, com questôes abertas e fechadas e temáticas referentes à identificação geral dos CAPSij, aos entendimentos e às percepçôes sobre intersetorialidade e à articulação intersetorial.

Para a localização, contato e convite aos participantes foram realizadas diferentes ações, descritas a seguir:

a) Identificação e localização dos CAPSij: a listagem com os CAPSij desta região foi obtida junto ao Sistema Eletrônico de Serviço de Informação ao Cidadão (e-SIC); no documento enviado pela Coordenação Nacional de Saúde Mental (abril 2015) constavam 103 equipamentos no Cadastro Nacional de Estabelecimentos de Saúde (CNES). Uma vez que a listagem não forneceu os dados para contato com os serviços, foram realizadas buscas no SCNES, sistema de busca virtual relacionado ao CNES, na internet e nas secretarias municipais de Saúde para obtenção do contato (número de telefone/e-mail). Para dois CAPSij, nenhuma informação para contato teve sucesso.

b) Estabelecimento de contato e convite: uma vez identificados os telefones de cada um dos CAPSij, seguiu-se o contato via telefone entre pesquisadora e gerência/ coordenação dos serviços para primeira apresentação da proposta de pesquisa. Foram realizadas no mínimo três tentativas de contato com cada um dos CAPSij presentes na listagem inicial. Ao todo, foram realizadas cerca de 600 tentativas de contato com os demais serviços (ligação, mensagem eletrônica e reunião presencial). Do total da amostra, cerca de 28 serviços náo responderam ao contato inicial (telefone errado, não atendia, coordenação não respondia ao telefonema).

c) Envio do projeto para apreciação: após o contato inicial com as gerências dos CAPSij, no que se refere ao processo de apreciação da proposta de pesquisa, três percursos de avaliação (pelas convidadas) foram efetivados:

i) a aprovação e o aceite ficaram restritos ao responsável pela gerência do CAPSij;

ii) a aprovação e o aceite das instâncias de gestão municipal atrelados ao aceite também da gerência do CAPSij; 
iii) submissão do projeto de pesquisa aos Comitês de Ética em Pesquisa das Secretarias Municipais de Saúde (SMS) e/ou prefeituras seguidos via Plataforma Brasil e às coordenaçôes regionais.

d) Devolutiva da análise do projeto (aprovação ou recusa) e envio dos questionários: cada instância deliberativa emitiu um parecer em relação ao convite para participação. As recusas representaram $5 \%(\mathrm{n}=5)$ da amostra total. No caso daqueles que aceitaram a participação, $(n=69)$ foram enviados para cada CAPSij uma Carta de Apresentação do Estudo destinada a toda equipe do serviço, cópia do Termo de Consentimento Livre e Esclarecido, Questionário de Pesquisa e parecer da SMS quando solicitado. Os questionários foram somente enviados para os serviços nos quais estes profissionais assentiram quanto à participação, posterior às aprovações institucionais. Assim, dos 69 convidados, 36 serviços efetivamente participaram do estudo.

Os questionários respondidos, após sistematização e organização, foram apresentados descritivamente. Para as questóes abertas, procedeu-se à análise categorial, proposta por Bardin (2011). Na apresentação das narrativas dos participantes que figuram neste estudo, a identificação ocorrerá por meio de letra $P$ (participante) seguida de numeral correspondente. Por exemplo: P01.

\section{Resultados e Discussão}

A seguir são apresentados os resultados que objetivam caracterizar os CAPSij participantes do estudo quanto a informaçóes como tempo de funcionamento e população de abrangência relacionados na tabela 1 , a seguir.

Tabela 1. Caracterização dos CAPSij participantes

\begin{tabular}{lc|c}
\hline & Quantidade de CAPSij n (\%) \\
\hline & 1 a 4 anos & $7(20 \%)$ \\
Tempo de funcionamento & 5 a 10 anos & $17(48 \%)$ \\
dos serviços & 11 a 15 anos & $9(26 \%)$ \\
& Mais de 15 anos & $2(6 \%)$ \\
\hline
\end{tabular}

continua... 


\begin{tabular}{lc|c}
\hline & Quantidade de CAPSij n (\%) \\
\hline 70 mil a 149 mil & $6(17)$ \\
150 mil a 250 mil & $9(26 \%)$ \\
População de abrangência & 251 mil a 500 mil & $12(34 \%)$ \\
& 501 mil a 750 mil & $7(20 \%)$ \\
& 750 mil a 1milhão & - \\
& mais de 1 milhão & $1(3 \%)$ \\
\hline
\end{tabular}

Fonte: Elaborada pelas autoras.

Parte considerável, cerca de $80 \%$ dos serviços têm mais de cinco anos de funcionamento, o que evidencia que se trata de serviços que têm uma dinâmica já conhecida e recolhem certa experiência com relação à população e ao projeto de funcionamento. Trata-se, portanto, de uma amostra, que independentemente da avaliação dos resultados, já pôde compreender e supostamente atender às premissas das políticas de saúde mental em voga.

Os dados referentes à populaçáo de abrangência dimensionam a demanda estimada de procura pelo serviço. Portarias indicam que o critério populacional para instalação de CAPSij em determinada localidade (município ou região) é de acima de 70 mil habitantes (BRASIL, 2011). Do conjunto de serviços presentes, nenhum se localiza em municípios com população abaixo do indicado. Contudo, expressiva parte, mais de $50 \%$, apresenta o triplo da população indicada, valendo revelar ainda que oito serviços (23\%) apresentam mais de 500 mil habitantes em sua área de abrangência, o que compromete sobremaneira a capacidade de articulação e a oferta assistencial destes serviços, tal como já destacado em estudo anterior (TAÑO; MATSUKURA, 2015).

Pesquisa de Garcia, Santos e Machado (2015) aponta que os CAPSij são insuficientes e mal distribuídos geograficamente. Ao tomarem como parâmetro as portarias anteriores que estabeleciam a existência de CAPSij em municípios com mais de 150 mil habitantes, evidenciaram que estes estavam presentes em apenas $60,4 \%$ numa média nacional. Ao se considerar a portaria 3.088, de 2011, que em sua republicação diminui para 70 mil o critério populacional, esta cobertura é certamente ainda muito mais insuficiente. O que mostra então é que a atenção a crianças e adolescentes, 
ainda que um compromisso prioritário pela Constituição Federal e pelo Estatuto da Criança e do Adolescente (BRASIL, 1995), não é traduzida em compromisso político e da gestão em diferentes níveis federativos no que concerne ao financiamento para a criação de novos equipamentos, manutenção e ampliação destes.

Com relação aos serviços que encaminham crianças e adolescentes para os CAPSij em tela, foi solicitado que os participantes indicassem ao menos os três equipamentos que mais realizam encaminhamentos, devendo ser apresentados em ordem decrescente, tal como apontado na Tabela 2, a seguir.

Tabela 2. Serviços/setores que mais encaminham para os CAPSij

\begin{tabular}{|c|c|c|c|c|c|}
\hline Serviços/setores & $1^{\circ}$ lugar & $2^{\circ}$ lugar & $3^{\circ}$ lugar & $\begin{array}{c}\text { Outras } \\
\text { posiçóes }\end{array}$ & $\begin{array}{l}\text { Total de } \\
\text { citaçóes }\end{array}$ \\
\hline $\begin{array}{l}\text { Escolas (municipais e estaduais) } \\
\text { e Secretaria Municipal de } \\
\text { Educação }\end{array}$ & 13 & 5 & 14 & 3 & 35 \\
\hline $\begin{array}{l}\text { Atenção Básica (USF, UBS, } \\
\text { NASF) }\end{array}$ & 13 & 9 & 1 & 11 & 34 \\
\hline Conselho Tutelar & 4 & 6 & 5 & 9 & 24 \\
\hline Demanda Espontânea/Famílias & 3 & 5 & 2 & 5 & 15 \\
\hline $\begin{array}{l}\text { Justiça (Vara da Infância, } \\
\text { Fórum, Ministério Público) }\end{array}$ & 0 & 3 & 2 & 8 & 13 \\
\hline $\begin{array}{l}\text { Secretaria de Assistência Social } \\
\text { e CRAS }\end{array}$ & - & - & 2 & 11 & 13 \\
\hline $\begin{array}{l}\text { Outros ambulatórios/ Centros de } \\
\text { Especialidade }\end{array}$ & - & 2 & 2 & 6 & 10 \\
\hline CREAS & - & 1 & - & 9 & 10 \\
\hline Hospitais/P.S./UPA & - & 1 & 3 & 5 & 9 \\
\hline $\begin{array}{l}\text { Serviço de Acolhimento } \\
\text { Institucional para Crianças e } \\
\text { Adolescentes (SAICA) }\end{array}$ & 1 & - & 1 & 5 & 7 \\
\hline $\begin{array}{l}\text { Ambulatórios de Saúde mental/ } \\
\text { Outros serviços de saúde mental }\end{array}$ & - & 3 & - & - & 3 \\
\hline
\end{tabular}

continua... 


\begin{tabular}{l|c|c|c|c|c}
\hline Serviços/setores & $\mathbf{1}^{\circ}$ lugar & $\mathbf{2}^{\circ}$ lugar & $\mathbf{3}^{\circ}$ lugar & $\begin{array}{c}\text { Outras } \\
\text { posiçóes }\end{array}$ & $\begin{array}{c}\text { Total de } \\
\text { citaçóes }\end{array}$ \\
\hline CER & - & - & 1 & 2 & 3 \\
\hline Saúde (sem especificação) & 1 & 1 & - & - & 2 \\
\hline ONGs e Instituiçóes parceiras & - & - & - & 2 & 2 \\
\hline Saúde privada & - & 1 & - & - & 1 \\
\hline CECCO & - & - & - & 1 & 1 \\
\hline APAE & - & - & - & 1 & 1 \\
\hline Fundação CASA & - & - & - & 1 & 1 \\
\hline Polícia Militar & - & - & - & 1 & 1 \\
\hline Hospital Psiquiátrico & - & - & - & 1 & 1 \\
\hline
\end{tabular}

${ }^{1}$ Uma vez que foram citados distintamente pelos participantes, CRAS e CREAS são destacados em categorias distintas.

Fonte: Elaborada pelas autoras.

Vale destacar, em relação aos dados apresentados, que a sistemática atrelada ao modelo de encaminhamento não sustenta necessariamente a articulação intersetorial e em rede. Contudo, com a finalidade de identificar as possíveis parcerias e contatos estabelecidos pelos serviços, entende-se que a alusão aos encaminhamentos pode ser útil na construção de entendimentos e outras análises sobre a prática intersetorial relacionada à atenção às crianças e aos adolescentes em sofrimento psíquico. Segundo os participantes, de modo geral, as primeiras instituiçôes/setores/serviços que mais encaminham crianças e adolescentes para o CAPSij são aquelas com as quais os trabalhadores mais mantêm contato para a construção compartilhada do entendimento e estratégias de cuidado para os casos. Nesse sentido, os resultados enunciados correspondem ao que tem sido apresentado na literatura acerca da construção de estratégias intersetoriais em que saúde, educação e assistência social têm sido os principais setores a apoiarem açôes conjuntas e mais compartilhadas de atenção (AZEVEDO; PELICIONI; WESTPHAL, 2012; DUARTE et al., 2010).

É inegável, e pode parecer já explorada à exaustão, a necessidade da articulação entre os serviços estratégicos, em que se incluem o CAPSij e a Atenção Básica. Entretanto, sabe-se que os desafios colocados para que essa prática se consolide também têm 
sido amplamente abordados (BRASIL, 2011; CAVALCANTE; JORGE; SANTOS, 2012; COUTO; DELGADO, 2016). Ainda que os dados iniciais apresentados não qualifiquem como têm ocorrido os contatos entre os distintos setores/serviços, sugere-se que o incremento e investimento neste domínio seja realizado.

Alguns CAPSij apontaram ainda que, por estarem articulados de acordo com o que preconiza a RAPS, os encaminhamentos realizados por outros setores são primeiramente referenciados para a Atenção Básica em Saúde que, posteriormente, com as demandas já mais bem delineadas, realizam o encaminhamento oportuno para os CAPSij. Estas açóes podem seguramente ofertar a possibilidade de que de fato a Atenção Básica assuma a centralidade da gestão do cuidado. Entretanto, podem também significar uma maior circulação das famílias até a obtenção da atenção devida. Salienta-se que este arranjo deve ser realizado conjuntamente com as ações de apoio matricial que poderão qualificar o entendimento e as ações das equipes da atenção primária, de modo a evitar peregrinações das famílias em busca do acolhimento adequado.

Quanto aos encaminhamentos provenientes da Fundação CASA, dos Serviços de Medida Socioeducativas, bem como de boa parte daqueles provenientes do sistema de Justiça, entende-se que este é um tema que carece de debate crítico constante. No mesmo sentido, verifica-se que hospitais psiquiátricos e Polícia Militar tiveram referências em dois CAPSij como instituiçóes expressivas no encaminhamento de crianças e adolescentes. Considerando a histórica trajetória de marginalização e criminalização das vidas dos adolescentes e jovens e as atuais proposiçóes de psiquiatrização/patologização dos problemas que estes enfrentam com a Justiça e com sistemas de ordenamento da cultura vigente (VICENTIN; GRAMKOW, 2010), buscar identificar compreensóes, objetivos, necessidades e saberes contidos nestes contatos é ação fundamental.

Se historicamente a institucionalização de jovens teve um caráter de correção social (TAÑO; MATSUKURA, 2014); hoje, ela segue do mesmo modo, contudo atrelada ainda ao paradigma psiquiátrico, que transforma relevantes problemas de ordem social em patologias, reafirmando a carga de marginalização e de exclusão a que estes jovens e adolescentes estão submetidos, ou ainda criminalizando suas condutas, expressóes e formas de se relacionar com o mundo. Para os serviços que trabalham na garantia dos direitos e no entendimento mais heterogêneo e diverso sobre saúde, em que se incluem os CAPSij, estes encaminhamentos em larga escala podem configurar 
uma ameaça. Estudos recentes têm apontado para essa problemática e têm insistido em que tais encaminhamentos seguem na linha da manutenção da ordem social (BARRETO; 2010; JOIA; OLIVEIRA; VICENTIN, 2016).

Por outro lado, estes dados podem também indicar que tais serviços/setores como Polícia Militar, Hospital Psiquiátrico e Fundação CASA reconhecem nos CAPSij a possibilidade de um cuidado para crianças e adolescentes articulado nos territórios e comunidades. Nesse sentido, é importante que a aproximação com tais instituiçôes possibilite uma reordenação das práticas e a afirmação de outras lógicas de cuidado que se oponham à centralidade do modelo psiquiátrico, criminalizador e patologizante para crianças e adolescentes, reiterados por estes fluxos de encaminhamento, tal como apresentados. É necessário assim que a consideração da rede em relação à centralidade dos CAPSij possa ser utilizada como forma de oportunizar a efetivação da Atenção Psicossocial tal como preconizada.

Em composição com os dados anteriores, e relacionado aos principais contatos realizados entre CAPSij e outros serviços e setores, foi solicitado que os participantes tratassem sobre os principais benefícios e dificuldades advindas destas açôes de aproximação. As respostas foram categorizadas e são apresentadas a seguir:

Quadro 1. Benefícios advindos dos contatos com a rede

\begin{tabular}{|c|c|c|}
\hline Categorias & Exemplos dos benefícios & Citaçóes \\
\hline $\begin{array}{l}\text { Corresponsabilizaçáo } \\
\text { e criação de redes } \\
\text { comprometidas }\end{array}$ & $\begin{array}{l}\text { - corresponsabilização (criança não é de um serviço) } \\
\text { - rede de suporte para o território (principalmente } \\
\text { para quem mora longe do CAPSij) } \\
\text { - execução da Intersetorialidade }\end{array}$ & 21 \\
\hline $\begin{array}{l}\text { Ampliação do olhar e } \\
\text { das açóes para sujeitos } \\
\text { e territórios }\end{array}$ & $\begin{array}{l}\text { - auxilia no entendimento integral da criança } \\
\text { - entendimento sobre interação nos diferentes } \\
\text { espaços que as crianças vivem } \\
\text { - produção de novos questionamentos } \\
\text { - reconhecimento das demandas } \\
\text { - mudança no funcionamento das escolas (equipe } \\
\text { mais disponível e questionadora) }\end{array}$ & 17 \\
\hline
\end{tabular}

continua... 


\begin{tabular}{|c|c|c|}
\hline Categorias & Exemplos dos benefícios & Citaçôes \\
\hline $\begin{array}{l}\text { Qualificação/ } \\
\text { efetivação das açóes }\end{array}$ & $\begin{array}{l}\text { - facilita o cuidado } \\
\text { - alinhamento de conceitos com educação } \\
\text { - melhora no manejo de professores em casos } \\
\text { complexos } \\
\text { - melhor entendimento da dinâmica escolar } \\
\text { - melhora na qualidade dos encaminhamentos }\end{array}$ & 14 \\
\hline $\begin{array}{l}\text { Apoia as equipes e o } \\
\text { trabalho }\end{array}$ & $\begin{array}{l}\text { - fortalecimento mútuo das equipes } \\
\text { - coesão da rede } \\
\text { - potencializa os serviços diante da incompletude } \\
\text { institucional } \\
\text { - dissipação do sentimento de isolamento das equipes }\end{array}$ & 12 \\
\hline $\begin{array}{l}\text { Apoia a construção de } \\
\text { alternativas de cuidado } \\
\text { condizentes com a } \\
\text { ampliaçáo da vida/ } \\
\text { respeito ao usuário }\end{array}$ & $\begin{array}{l}\text { - diminuição de processos de institucionalização } \\
\text {-amplia processo de reabilitaçáo social }\end{array}$ & 7 \\
\hline $\begin{array}{l}\text { Melhora no contato/ } \\
\text { apoio/atenção às } \\
\text { famílias }\end{array}$ & - potencialização do cuidado com as famílias & 4 \\
\hline $\begin{array}{l}\text { Reconhecimento do } \\
\text { território }\end{array}$ & $\begin{array}{l}\text { - conhecimento dos equipamentos dos territórios } \\
\text { - desenho do território a partir das escolas } \\
\text { - acompanhamento das necessidades dos territórios }\end{array}$ & 4 \\
\hline Sustenta o PTS & - construçáo conjunta do PTS & 2 \\
\hline $\begin{array}{l}\text { Produz a integralidade } \\
\text { do cuidado }\end{array}$ & - auxilia construção do cuidado integral & 2 \\
\hline Não respondeu & - & 2 \\
\hline Promoção da saúde & - promoção da saúde & 1 \\
\hline Outros & $\begin{array}{l}\text { - realização de avaliaçóes clínicas (descartar } \\
\text { problemas orgânicos) }\end{array}$ & 1 \\
\hline
\end{tabular}

Fonte: Elaborado pelas autoras. 
Ao que se percebe nas contribuiçôes dos participantes, a ideia de corresponsabilização é entendida como a possibilidade deste agenciamento comum entre setores e instituições para o processo de produção de saúde ampliada, em que se afirma a necessidade da garantia de direitos e pactuação. Pelo que é entâo apontado pelos participantes, a corresponsabilização efetiva a potencialização do trabalho e contribui para a direção para a prática da intersetorialidade.

$\mathrm{Na}$ afirmação dos participantes de que a corresponsabilização se caracteriza pela compreensão de que a criança/adolescente não é de responsabilidade restrita de somente um serviço pode estar contida a premissa de que esses sujeitos não podem ter suas vidas, demandas e necessidades em torno de tais experiências. Esse posicionamento se alinha ao que Reforma Psiquiátrica e Atenção Psicossocial vêm insistentemente buscando transformar: a relação social com a loucura e a objetificação do sujeito que sofre em seu aprisionamento quase absoluto à identidade de louco/ doente mental e para as crianças e adolescentes, sob a pecha de transtornadas (AMARANTE, 2007; FERREIRA, 2008).

Tanto em termos de políticas de saúde como também pelo que se verifica nos resultados apresentados neste estudo, a corresponsabilização enquanto processo positivo na construção da relação entre os setores movimenta os agentes para a ampliação do olhar e do entendimento sobre as situaçôes com as quais se deparam e nas quais devem/podem intervir. Nesta direção, a Política Nacional de Humanização (PNH) prevê que a corresponsabilização encaminha a ação para a efetuação da clínica ampliada (BRASIL, 2008), evidenciada neste estudo como possibilidade de expansão dos recursos, entendimentos, trocas e defesa da integralidade do cuidado.

Proposiçôes e orientaçôes dos Fóruns Nacionais de Saúde Mental Infantojuvenil (BRASIL, 2014) bem como os trabalhos de Couto e Delgado (2016) e de Lourenço (2017) apontam para essa construção das açôes em rede como prioritária para o campo da atenção psicossocial infantojuvenil e mesmo indicam que o trabalho que se constitui nesta perspectiva é muito mais potente e efetivo, mesmo em regióes nas quais faltam CAPSij.

Além da sustentação do trabalho, a criatividade e a imaginação para a criação de outras estratégias de cuidado e de produção de saúde podem ser colocadas em marcha com arranjos mais coletivos de trabalho. Os benefícios do contato com a rede não se direcionam apenas à troca de informaçôes, outrossim à elaboração 
conjunta de outras propostas e estratégias de atenção, incorporando o cuidado com as famílias e comunidades também enquanto prioridades.

Alinhamentos em relação ao trabalho com as famílias também foram indicados como importantes ganhos do trabalho conjunto, bem como o melhor reconhecimento do território. Entende-se que estes benefícios citados são essenciais para o trabalho das equipes de CAPSij; o contato com as famílias de cada localidade, com serviços como da Atenção Básica, da educação e da assistência, que no geral estão responsabilizados por extensóes geográficas e populacionais mais reduzidas, fornecem informaçóes e qualificam o olhar dos profissionais dos CAPSij para as singularidades de cada território/comunidade aos quais dáo cobertura.

Quanto às principais dificuldades assinaladas relativas ao contato com os serviços e instituiçōes com os quais os CAPSij mais mantêm contato e parceria, o Quadro 2 a seguir apresenta as categorias analisadas:

Quadro 2. Dificuldades advindas dos principais contatos com a rede

\begin{tabular}{|c|c|c|}
\hline Categoria & Exemplos das dificuldades & Citaçóes \\
\hline $\begin{array}{l}\text { Coletivizar o } \\
\text { compromisso com a } \\
\text { atençáo (dinâmica, } \\
\text { negociaçáo e } \\
\text { entendimento) }\end{array}$ & $\begin{array}{l}\text { - desconhecimento dos fluxos por parte da rede } \\
\text { - resistência com relação à implantação da RAPS e da } \\
\text { Atenção Psicossocial } \\
\text { - diferentes concepçóes de cuidado } \\
\text { - manutenção dos acordos e combinados nas decisões } \\
\text { coletivas }\end{array}$ & 16 \\
\hline $\begin{array}{l}\text { Questóes } \\
\text { relacionadas à } \\
\text { Atençáo Básica em } \\
\text { Saúde (AB) }\end{array}$ & $\begin{array}{l}\text { - corresponsabilização com a } \mathrm{AB} \\
\text { - falta de profissionais de saúde mental na } \mathrm{AB} \\
\text { - pouco lugar para os adolescentes na } \mathrm{AB} \\
\text { - pouco acompanhamento das famílias na } \mathrm{AB} \\
\text { - dificuldade na realização do apoio matricial }\end{array}$ & 15 \\
\hline $\begin{array}{l}\text { Questóes } \\
\text { relacionadas à escola }\end{array}$ & $\begin{array}{l}\text { - tempo da escola é diferente do tempo da criança } \\
\text { - crianças sem projeto pedagógico e sem material adaptado } \\
\text { - falta de preparo dos professores para o trabalho com } \\
\text { alunos diferentes demandas } \\
\text { - solicitação de laudos que justifiquem o afastamento da } \\
\text { escola/reduçáo do horário } \\
\text { - discurso de medicalização (escola) } \\
\text { - quebra do paradigma da exclusão na escola }\end{array}$ & 12 \\
\hline
\end{tabular}




\begin{tabular}{|c|c|c|}
\hline Categoria & Exemplos das dificuldades & Citaçóes \\
\hline Corresponsabilizaçáo & $\begin{array}{l}\text { - dificuldade de compartilhamento no cuidado } \\
\text { - presença da lógica do encaminhamento sem } \\
\text { implicação }\end{array}$ & 10 \\
\hline $\begin{array}{l}\text { Patologização e } \\
\text { medicalizaçáo das } \\
\text { questóes }\end{array}$ & $\begin{array}{l}\text { - lógica do diagnóstico (se sobrepóe ao diálogo sobre as } \\
\text { demandas e problemas sociais) } \\
\text { - produção de escuta para além do sintoma } \\
\text { - valorização da cultura da medicalização pela rede } \\
\text { intersetorial } \\
\text { - cobrança quanto à definição rápida do diagnóstico } \\
\text { - solicitaçóes centradas no encaminhamento para } \\
\text { atendimento médico }\end{array}$ & 10 \\
\hline $\begin{array}{l}\text { Escassez (recurso e } \\
\text { território) }\end{array}$ & $\begin{array}{l}\text { - transporte para os encontros } \\
\text { - precarização dos serviços (internet, telefone) } \\
\text { - dificuldade de acesso (unidades em zona de risco e } \\
\text { comunidades distantes) }\end{array}$ & 7 \\
\hline $\begin{array}{l}\text { Desconhecimento da } \\
\text { rede sobre a funçáo } \\
\text { dos CAPSij }\end{array}$ & $\begin{array}{l}\text { - desconhecimento dos serviços no que concerne } \\
\text { à proposta do CAPSij (grande demanda de } \\
\text { encaminhamentos desnecessários/equivocados) }\end{array}$ & 3 \\
\hline Agenda & - irregularidade dos encontros & 3 \\
\hline $\begin{array}{l}\text { Questóes } \\
\text { relacionadas ao } \\
\text { Conselho Tutelar }\end{array}$ & $\begin{array}{l}\text { - falta de alinhamento, } \\
\text { - encaminhamentos desnecessários }\end{array}$ & 2 \\
\hline $\begin{array}{l}\text { Relacionados às } \\
\text { famílias }\end{array}$ & $\begin{array}{l}\text { - resistência da família } \\
\text { - atendimentos para familiares fora do CAPSij }\end{array}$ & 2 \\
\hline $\begin{array}{l}\text { Judicialização dos } \\
\text { casos/ questóes } \\
\text { relacionadas ao } \\
\text { Judiciário }\end{array}$ & $\begin{array}{l}\text { - judicialização dos casos (principalmente pelos CREAS } \\
\text { e SAICAS) } \\
\text { - contato com a Justiça }\end{array}$ & 2 \\
\hline $\begin{array}{l}\text { Dinâmica dos } \\
\text { encaminhamentos }\end{array}$ & $\begin{array}{l}\text { - encaminhamentos mal preenchidos } \\
\text { - encaminhamento equivocados }\end{array}$ & 2 \\
\hline Não respondeu & - & 2 \\
\hline $\begin{array}{l}\text { Questóes } \\
\text { relacionadas com a } \\
\text { Assistência Social }\end{array}$ & - contato com a assistência & 1 \\
\hline
\end{tabular}




\begin{tabular}{l|l|c}
\multicolumn{1}{c|}{ Categoria } & \multicolumn{1}{c|}{ Exemplos das dificuldades } & Citaçóes \\
\hline $\begin{array}{l}\text { Questóes } \\
\text { relacionadas às } \\
\text { equipes dos CAPSij }\end{array}$ & - desgaste da equipe do CAPSij & 1 \\
\hline $\begin{array}{l}\text { Complexidade dos } \\
\text { casos acompanhados }\end{array}$ & - complexidade dos casos & 1 \\
\hline
\end{tabular}

Fonte: elaborado pelas autoras.

As dificuldades relacionadas ao contato com os principais parceiros referem-se substancialmente à construção de um compromisso comum de cuidado, que esteja de fato pautado nas necessidades das crianças, adolescentes e suas famílias, para além da especificidade de determinado sintoma que estas supostamente possam apresentar.

Tais empecilhos para a realização de u m trabalho mais articulado estão certamente localizados nas raízes históricas da consolidação das práticas para atenção às crianças e adolescentes, em que as açôes se destinavam ao controle e ordenamento social pautadas na fragmentação da assistência e, consequentemente, no não alinhamento das práticas e entendimentos (COUTO; DELGADO, 2015).

As contribuiçóes que tratam da dificuldade de ordenamento de um projeto comum de cuidado revelam o quanto isso pode ser reflexo da resistência acerca das atuais propostas para um cuidado em saúde mental na perspectiva da integralidade e da produção de saúde, vida e cidadania. Em termos gerais, é assinalado que a resistência é fruto do não alinhamento, exemplificado pelo não compromisso com as novas lógicas de cuidado que centralizam a atenção no acolhimento, clínica ampliada e desnaturalização/problematização da lógica de encaminhamento. Entretanto, cabe assinalar que, assim como aponta Gelinski (2011), as lógicas de corresponsabilização demandam que os atores envolvidos de fato entendam e tenham conhecimento sobre o ordenamento e o esquema de regras colocado em determinada realidade. Dessa forma, ainda que haja discordâncias explícitas, o desconhecimento das novas lógicas de cuidado implicam nas possibilidades de prosseguimento do trabalho.

Ainda há muito que se avançar na constituição de açóes que verdadeiramente defendam e respeitem os direitos das crianças e adolescentes e que possam assegurar suas participaçôes ativas na sociedade. Mesmo com legislações e documentos que deveriam fortalecer estas práticas, como a Constituição Federal (artigo 227) e o 
Estatuto da Criança e do Adolescente (BRASIL, 1988; 1990), falta muito para a consolidação das práticas que reconheçam sua cidadania e a necessidade de açóes que operem na integralidade. A persistência de olhares de tradição assistencialista na proteção às crianças e aos adolescentes determina então os entendimentos e as condutas técnicas sobre estas, em formas de operacionalização dos recursos e da gestão que seguem perpetuando os modelos fragmentados assinalados (MALFITANO, 2013).

De modo geral, são estas mesmas questôes que atravessam tanto as consideraçóes sobre os desafios do contato com a Atenção Básica, bem como com a Educação, destacados no quadro anterior. Especialmente em relação à Atenção Básica, a ampliação do acesso e do acompanhamento da população em experiência de sofrimento psíquico é destacada tanto na Portaria GM 3.088/2011, que institui a Rede de Atenção Psicossocial, como na Política Nacional de Atenção Básica, de 2012, na qual se assegura a relevância de a gestão do cuidado ocorrer nos serviços de Atenção Básica mediante o compartilhamento das açóes, considerando os sujeitos em suas singularidades e complexidade na integralidade do cuidado (BRASIL, 2011; 2012).

Sobre este assunto, as contribuiçôes dos participantes fazem revelar a importância das açóes de apoio matricial, enquanto estratégias de enfrentamento das realidades marcadas pela fragmentação do trabalho; falta de comunicação e desconhecimento sobre saúde mental. Destaca-se como relevante o fato de que crianças e adolescentes são pouco ou nada contemplados nas ações da Atenção Básica e para os quais os trabalhadores muitas vezes relatam resistências ao contato e à vinculação (CAVALCANTE; JORGE; SANTOS, 2012; LOURENÇO, 2017).

Já o termo medicalização, presente neste quadro, atesta sobre tema corrente na atualidade acerca dos processos discursivos e interventivos que atravessam crianças, adolescentes e suas formas de se relacionarem com o mundo. Destaca-se que o uso do termo medicalização foi apontado pelos próprios participantes, configurando tanto em categoria temática como em marco de análise para a produção de um discurso afirmado nos encontros com a rede. Salienta-se que, no campo da saúde e da educação, este termo, assim como desenvolvem Carvalho e colaboradores (2015), tem se referido a uma multiplicidade de sentidos e intençóes.

Para critérios de apresentação neste trabalho, e tomando por norte o referencial utilizado por Collares e Moyses (1994), entende-se o uso abrangente do termo medicalização como a ocultação dos determinantes sociais, políticos, culturais e históricos na produção ideológica de individualização de problemáticas que são 
então compreendidas e classificadas segundo normas oriundas da medicina e, mais atualmente, de outras disciplinas do campo da saúde, correspondendo então a processos de doença/transtornos. Diferentes autores têm atualmente tratado esta temática em substituição do termo medicalização pelos termos patologização (COLLARES; MOYSES, 1994; COLLARES; MOYSES; RIBEIRO, 2013), biomedicalização (CARVALHO; et al., 2015).

Em relação às crianças e adolescentes, esse debate é constante e deve mesmo constituir tomada de posicionamento dos diferentes atores sociais do campo da atenção aos direitos destas, uma vez que se reconhece que, para estas, os processos de patologização da vida são mais intensos e dominam grande parte do discurso educacional hoje. Estes entendimentos contemplam parte importante das dificuldades assinaladas pelos gestores com relação às escolas, e também estão presentes em outra categoria separada quando tratam mesmo dos processos de patologização e medicalização aos quais estão submetidas as populaçôes acompanhadas.

Constituindo-se em fenômeno social e não somente restrito ao campo médico, a patologização da vida, ao individualizar problemas sociais e políticos, encobre a necessária e urgente discussão sobre o sistema educacional contemporâneo e outras instituiçôes e grupos responsáveis pelo acompanhamento e garantia de direitos de crianças e adolescentes. É necessário, portanto, o reconhecimento de que, no geral, o sofrimento das pessoas está associado também à ausência de redes de suporte, de acesso às políticas sociais e de direitos (LUGON, 2016; COLLARES; MOYSES; RIBEIRO, 2013; OMS, 2001).

É exatamente em relação a esta problemática que a intersetorialidade como estratégia de intervenção e de gestão se mostra potente, na construção de um compromisso compartilhado com a diminuição das desigualdades sociais e outros sofrimentos, como aponta Inojosa (2001). O exercício intersetorial contribui também para o questionamento em relação aos entendimentos sobre o sofrimento psíquico que se fundamentam em uma linearidade biomédica oriunda dos diagnósticos nosológicos e classificatórios que condicionam a compreensão "técnica" sobre os contextos de vida por meio de checklists e protocolos (LUGON, 2016).

Sobre a função do CAPSij na construção de outros entendimentos acerca do sofrimento psíquico a serem compartilhados com a rede, a narrativa de um dos participantes, a seguir, indica de que forma é possível romper com movimentos de patologização da vida de crianças e adolescentes. 


\begin{abstract}
Neste percurso, encontramos dificuldade quanto à expectativa que cada serviço tem um do outro. Muitas vezes o pedido de intervenção do CAPSij, principalmente quando se trata de questôes de comportamento agitado, é para darmos uma medicação; ofertar para a criança/adolescente uma consulta com o médico; afastar a criança da escola ou dar um laudo que justifique o horário reduzido; ou mesmo deixá-la mais sedada para evitar conflitos com colegas no SAICA, escola ou outros espaços que frequente. Esses são exemplos no quais verifica-se que a todo momento é necessário o CAPSij apresentar seu trabalho e sua função na RAPS, auxiliando a rede na compreensão desse papel. Mas essencialmente entendemos que a missão do CAPSij também está em facilitar a ampliação da compreensão do sofrimento psíquico de crianças/adolescentes, ajudando a rede a entender a importância de dar voz a esse sofrimento, auxiliando no cuidado com os mesmos, que náo se resumem a medicação ou médico. Buscamos auxiliar na ampliaçâo da compreensão daquele comportamento, e não só na eliminação de um comportamento não considerado o esperado. Entendemos que essas ações fazem parte da missão do CAPSij. (P29)
\end{abstract}

O desconhecimento que o restante da rede tem dos objetivos e formas de atuação dos CAPSij parece indicar um mea culpa em relação aos processos de trabalho mais complexos, os quais o excerto anterior ilustra com exatidão e competência. Ponderando que grande parte dos serviços em tela traz mais de cinco anos de exercício, as dificuldades de interlocução se direcionam para os dois vértices da relação, salientando ainda tratarem-se dos parceiros mais frequentes, como assinala a questão.

É preciso reconhecer que os saberes e as açôes que circulam na atenção psicossocial são, em certa medida, complexos, elaborados e possivelmente de difícil compreensão pelos diferentes atores que circulam nas redes socioassistenciais e intersetoriais de atenção à infância e adolescência, no sentido de que muitas vezes se colocam em contracorrente à lógica atual de produção de doença e de patologização da vida e do social. Nesse contexto, o desconhecimento das outras instituiçóes sobre as especificidades do CAPSij pode servir como início de um trabalho que referencie a importância da atenção psicossocial para crianças e adolescentes e funde novas relações, mais cooperativas e horizontalizadas entre setores, famílias, serviços e comunidades.

\title{
Consideraçôes finais
}

O presente estudo, que teve como objetivo principal identificar como tem sido produzido o trabalho intersetorial nos Centros de Atenção Psicossocial Infantojuvenis (CAPSij), pautou-se na premissa da avaliação triangulação de métodos em sua etapa de análise diagnóstica. No que concerne aos procedimentos envolvidos, entende-se que esta etapa quantitativa/exploratória evidenciou aspectos mais gerais 
sobre este exercício, bem como destacou as percepçóes dos gestores acerca desta. Impasses, mas, sobretudo as potências desta estratégia foram reveladas por meio das contribuiçôes, no desenho concreto da condução da atenção psicossocial para crianças e adolescentes.

Nesse sentido, o enfoque dado, inclusive aos procedimentos metodológicos adotados para a execução do estudo, indicou questóes relevantes sobre as dificuldades de acesso e contato com os equipamentos estratégicos para a afirmação do modo de Atenção Psicossocial nos diferentes territórios. Tais contextos indicam, sobremaneira, a necessidade de que se viabilizem financiamento e qualificação aos serviços instalados, uma vez que a dificuldade de acesso pode certamente não afirmar-se somente para as pesquisadoras, bem como para a comunidade em geral.

De modo geral, a pesquisa revelou baixa cobertura dos CAPSij para a população da região. Destaca-se, assim, que até para o Estado de São Paulo, que concentra cerca de $25 \%$ de todos os CAPSij do território nacional, este número ainda é muito aquém do necessário. Os CAPSij têm respondido por áreas de abrangência imensas, com serviços inchados e certamente sem a capacidade devida para acompanharem todas as demandas e especificidades do território.

$\mathrm{O}$ estudo indicou também que condutas de controle seguem em curso, tal como consta nos encaminhamentos realizados pela Fundação CASA, Hospitais Psiquiátricos, Polícia Militar, entre outras instituições, notada e historicamente responsáveis pela patologização, criminalização e violação de direitos de crianças e adolescentes. Ainda que se entenda que os CAPSij podem oferecer um cuidado mais ampliado e a problematização das açôes de psiquiatrização da vida destes jovens, sabe-se que o encaminhamento excessivo e constante por parte destas instituiçôes é resquício e sinal de uma lógica de responsabilização da saúde pelas questôes socioculturais, econômicas e políticas a que um grupo está submetido, transformando problemas sociais em patologias.

É urgente que as equipes dos CAPSij e de outros serviços se engajem na problematização institucional e política desta realidade, reconhecendo que a reprodução social destas lógicas se afirma nas condutas das redes. É necessário ainda que, na produção dos encontros com jovens e adolescentes nestas situaçôes, haja espaço para debates e construçôes que desmoronem com as verdades calcificadas em torno das adolescências e juventudes, sobretudo as pobres, negras e periféricas, em termos coletivos, institucionais e sociais. 
Quantos às potencialidades e benefícios do trabalho intersetorial, na medida em que os contatos se estabelecem, são tecidas redes de suporte não somente para os usuários dos serviços, mas também para os profissionais. As ferramentas que possibilitam a ampliação da comunicação e a troca de saberes, pensamentos e experiências produzem uma sensação de parceria e de contato que alivia a sobrecarga de trabalho e sustenta a duração das intervençôes. Especialmente com relação à qualificação das açôes, os coordenadores citaram, em grande quantidade, os benefícios decorrentes do contato com as escolas no sentido da melhora da percepção de educadores com relação à saúde mental e às crianças e aos adolescentes em sofrimento psíquico.

Com relação às escolas, o montante de citaçóes indica a necessidade de aprimoramento das relaçôes com estas e com suas instâncias gestoras. Aponta-se isso, uma vez que hoje é a escola a principal instituiçáo social de circulaçáo para as crianças e adolescentes, ainda que pesem as dificuldades para a inclusão e permanência daquelas que estão em trajetos de sofrimento psíquico. Defende-se que é a partir do acesso e agenciamento com esta instituição que possivelmente as trajetórias de patologização da vida de crianças e adolescentes poderão ser transformadas, bem como as situaçóes graves de alijamento escolar poderão ser resolvidas.

Ainda que os coordenadores dos CAPSij tratem da dificuldade de constituição de açôes coletivas que garantam o trabalho intersetorial, esperar que a rede se constitua formalmente para assim então "funcionar" parece uma atitude que pode afastar/diminuir as capacidades analíticas e de engajamento de trabalhadores para esta empreitada. Salienta-se que não se trata de negar as dificuldades, embates e obstáculos colocados na constituição das redes, outrossim de assinalar que estas são desafios inerentes aos processos de gestáo mais compartilhada e horizontalizada de cuidado aos quais as crianças, adolescentes, famílias e suas comunidades têm direito.

Por fim, entende-se que o estudo ora apresentado contribui para um posicionamento cada vez mais efetivo sobre a constituição das redes como elemento prioritário para a consolidação de uma atençáo em saúde mental para crianças e adolescentes, mesmo em territórios dos quais os próprios CAPSij ainda não fazem parte. A rede então assume a centralidade do cuidado, possibilitando que os recursos e dispositivos locais sejam potencializados ainda que um ou outro serviço falte a esse agenciamento.

Sugere-se que futuros estudos possam contemplar as outras regiôes do país, no que concerne à constituição da intersetorialidade para a defesa da atenção psicossocial 
para crianças e adolescentes, destacando, sobretudo, as singularidades locorregionais e as capacidades inventivas e de articulação destas equipes. ${ }^{3}$

\section{Referências}

AMARANTE, P. Saúde mental e atenção psicossocial. Rio de Janeiro: Editora Fiocruz, 2007.

AZEVEDO, E.; PELICIONI, M.C.F.; WESTPHAL, M.F. Práticas intersetoriais nas políticas públicas de promoção à saúde. Physis: Revista de Saúde Coletiva. Rio de Janeiro, v. 22, n. 4, p. 1333-1356, 2012.

BARDIN, L. Análise de conteúdo. São Paulo: Ediçôes 70, 2011.

BARRETO, C. A adolescência, as medidas e a saúde mental: uma cota de liberdade. In.: LAURIDSEN-RIBEIRO, E.P.P; TANAKA, O.Y. (Orgs.). Atenção em saúde mental para crianças e adolescentes no SUS. São Paulo: Hucitec, 2010, p.352-363.

BRASIL. Senado Federal. Constituição da República Federativa do Brasil. Organização de Alexandre de Moraes. 16.ed. São Paulo: Atlas, 2000. . Estatuto da Criança e do Adolescente. $5^{\mathrm{a}}$ ed. São Paulo: Saraiva, 1995. 210p.

. Ministério da Saúde. Fórum Nacional de Saúde Mental Infantojuvenil: recomendaçôes de 2005 a 2012. Brasília: Ministério da Saúde; 2014.

. Ministério da Saúde. Conselho Nacional do Ministério Público. Atenção Psicossocial a Crianças e Adolescentes no SUS: tecendo redes para garantir direitos. Brasília: Ministério da Saúde, 2014b.

. Ministério da Saúde. Saúde Mental em Dados - 12, ano 10, n.12. Informativo eletrônico. Brasília: outubro de 2015.

- Secretaria de Atenção à Saúde. Departamento de Atenção Básica. Política Nacional de Atenção Básica. Brasília: Ministério da Saúde; 2012.

. Ministério da Saúde. Portaria n. 687, de 30 de março de 2006. Aprova a Política Nacional de Promoção da Saúde. Brasília, 2006.

Decreto 3088, de 23 de dezembro de 2011 (republicado). Institui a Rede de Atenção Psicossocial para pessoas com sofrimento ou transtorno mental e com necessidades decorrentes do uso de crack, álcool e outras drogas, no âmbito do Sistema Único de Saúde (SUS). Ministério da Saúde. Governo Federal. Brasília, 2011.

- Ministério da Saúde. Secretaria de Atenção à Saúde. Núcleo Técnico da Política Nacional de Humanização. Documento Base para Gestores e Trabalhadores do SUS. Brasília: Ministério da Saúde, 2008. 
CARMO, M.E.; GUIZARDI, F.L. Desafios da intersetorialidade nas políticas públicas de saúde e assistência social: uma revisão do estado da arte. Physis: Revista de Saúde Coletiva. Rio de Janeiro, v. 27, n. 4, p. 1265-1286, dez. 2017.

CARVALHO; S.R.; et al. Medicalização: uma crítica (im)pertinente? Physis: Revista de Saúde Coletiva. Rio de Janeiro, v. 25, n.4, p. 1251-1269, 2015.

CAVALCANTE; C.M.; JORGE, M.S.B; SANTOS, D.C.M. Onde está a criança? Desafios e obstáculos ao apoio matricial de crianças com problemas de saúde mental. Physis: Revista de Saúde Coletiva. Rio de Janeiro, v. 22, n. 1, p. 161-178, 2012.

COLLARES, C.A.L.; MOYSES, M.A.A. A transformação do espaço pedagógico em espaço clínico (A patologização da educação). Série Ideias, São Paulo: FDE, v.23, p. 25-31, 1994.

COLlARES, C.A.L.; MOYSES, M.A.A.; RIBEIRO, M.C.F. Apresentação. In.:

(Orgs.). Novas capturas, antigos diagnósticos na era dos transtornos. Campinas: Mercado de Letras, 2013, p. 15-20.

COUTO, M.C.V.; DELGADO, P.G.G. Intersetorialidade: exigência da clínica na atenção psicossocial. In: LAURIDSEN-RIBEIRO, E.P.P; TANAKA, O.Y. (Orgs.). Atenção em saúde mental para crianças e adolescentes no SUS. São Paulo: Hucitec, 2010, p. 217-279.

. Crianças e adolescentes na agenda política da saúde mental brasileira: inclusão tardia, desafios atuais. Psicologia Clínica. Rio de Janeiro, v. 27, n. 1, p. 17-40, 2015.

- Presença viva da saúde mental no território: construção da rede pública ampliada de atenção para crianças e adolescentes. In. LAURIDSEN-RIBEIRO, E.; LYKOUROPOULOS, C.B. (Orgs.). O Capsi e o desafio da gestão em Rede. São Paulo: Hucitec, 2016, p.161-192.

DELGADO, P.G.G. Limites para a inovação e pesquisa na reforma psiquiátrica. Physis: Revista de Saúde Coletiva. Rio de Janeiro, v. 25, n. 1, p. 13-18, 2015 a.

. O desafio da produçáo de conhecimento sobre a reforma psiquiátrica brasileira. Ciência e Saúde Coletiva. Rio de Janeiro, v. 20, n. 2, p. 312, 2015 b.

DUARTE, C.S. et al. A rede pública ampliada de atenção à saúde mental da crianças e do adolescente: estudo-piloto em quatro localidades do estado do Rio de Janeiro. In.: LAURIDSENRIBEIRO, E.P.P; TANAKA, O.Y. (Orgs.). Atenção em saúde mental para crianças e adolescentes no SUS. São Paulo: Hucitec, 2010.p. 280-302.

FERREIRA, T. G. As novas nomeaçóes do adoecimento psíquico das crianças e adolescentes na contemporaneidade e o cuidado no tratamento (distúrbios alimentares, hiperatividade, toxicomanias e depressão infantil). Jornada Estadual de Saúde Mental da Criança e do Adolescente, 21 e 22 agosto de 2008, CERSAMI Betim.

GARCIA, G.Y.; SANTOS, D.N.; MACHADO, D.B. Centros de Atenção Psicossocial Infantojuvenil no Brasil: distribuição geográfica e perfil dos usuários. Cadernos de Saúde Pública. Rio de Janeiro, v.31, n. 12, p.2649-2654, 2015. 
GELINSKI, C.R.O.G. A questão da corresponsabilidade prevista na Estratégia de Saúde da Família. Politica \& Sociedade. Florianópolis, v. 10, n. 19, 2011.

INOJOSA, R.M. Sinergia em política e serviços públicos: desenvolvimento social com intersetorialidade. Cadernos FUNDAP, São Paulo, n.22, p. 102-110, 2001.

JOIA, J.H.; OLIVEIRA, A.; VICENTIN, M.C.G. O que as trajetórias de atenção a crianças e adolescentes que fazem uso de drogas nos ensinam sobre o cuidado em rede? In. LAURIDSENRIBEIRO, E.; LYKOUROPOULOS, C.B. (Orgs.). O Capsi e o desafio da gestão em Rede. São Paulo: Hucitec, 2016, p. 265-279.

LOURENÇO, M.S.G. Saúde mental infantojuvenil: identificando realidades de municípios que não contam com CAPS infantojuvenil, a partir da Atenção Básica em Saúde. 2017. Dissertação (Mestrado em Terapia Ocupacional) - Programa de Pós Graduação em Terapia Ocupacional, Centro de Ciências Biológicas e da Saúde, Universidade Federal de São Carlos, São Carlos-SP, 2017.

LUGON, R. Breves reflexôes e paradoxos sobre a psiquiatria nos CAPSI. In.: LAURIDSENRIBEIRO, E.; LYKOUROPOULOS, C.B. (Orgs.). O Capsi e o desafio da gestão em Rede. São Paulo: Hucitec, 2016, p. 108-115.

MALFITANO, A.P.S. Intersetorialidade e estratégias de atenção na rede de assistência à criança e ao adolescente. In.: MANZINI, E.J. (Org.). Educação especial e inclusão: temas atuais. São Carlos: Marquezine \& Manzini: ABPEE; 2013, p. 189-204.

MENDES, R.; AKERMAN, M. Intersetorialidade: reflexôes e práticas. In.: FERNANDES, J.C.A.; MENDES, R. Promoção da Saúde e gestão local. São Paulo: Aderaldo \& Rothchild: CEPEDOC, 2007, p. 85-109.

MINAYO, M.C.S.; ASSIS, S.G.; SOUZA, E.R. (Orgs.) Avaliação por triangulação de métodos: abordagem de programas sociais. Rio de Janeiro: Editora Fiocruz, 2005.

ORGANIZAÇĀO MUNDIAL DA SAÚDE. Organização Pan-Americana da Saúde. Relatório sobre a saúde no mundo: saúde mental - Nova concepção, nova esperança. Genebra: WHO, 2001. . Atlas - Child and Adolescent Mental Health Resources: global concerns, implications of future. 2005.

TAÑO, B.L.; MATSUKURA, T.S. Os Centros de Atenção Psicossocial Infantojuvenis: características organizacionais e práticas de cuidado. Revista de Terapia Ocupacional da USP. São Paulo, v. 25, n. 3, p. 208-216, 2014.

- Saúde mental infantojuvenil e os desafios do campo: reflexóes a partir do percurso histórico. Cadernos de Terapia Ocupacional da UFSCar. São Carlos, v. 23, n. 2, 2015. 
VICENTIN, M.C.G.; GRAMKOW, G. Que desafios os adolescentes autores de ato infracional colocam ao SUS? Algumas notas para pensar as relaçóes entre saúde mental, justiça e juventude. In.: LAURIDSEN-RIBEIRO, E.P.P; TANAKA, O.Y. (Orgs.). Atenção em saúde mental para crianças e adolescentes no SUS. São Paulo: Hucitec, 2010. p. 337-351.

ZANIANI, E.J.M.; LUZIO, C.A. A intersetorialidade nas publicaçôes acerca do Centro de Atenção Psicossocial Infantojuvenil. Psicologia em Revista, v. 20, n. 1, p. 56-77, 2014.

\section{Notas}

${ }^{1}$ Ainda que nos documentos oficiais e na literatura corrente a sigla para os Centros de Atenção Psicossocial Infantojuvenis seja apresentada por "CAPSi", neste trabalho essa sigla será apresentada acrescentada da letra "j" - CAPSij. Demarca-se, com isso, a necessidade de consideração da população adolescente e jovem nesses equipamentos, a partir, que seja, da discursividade aqui apresentada.

${ }^{2}$ Este estudo contou com financiamento da CAPES - Coordenação de Aperfeiçoamento de Pessoal de Nível Superior e é parte integrante de pesquisa de doutorado da primeira autora, não apresentando conflito de interesses.

${ }^{3}$ B. L. Tãno elaborou e executou a pesquisa, análise dos dados, redação do manuscrito. T. S. Matsukura orientou o projeto de pesquisa, análise dos resultados, revisão da versão final do manuscrito. 


\section{Abstract}

Intersectoriality and care in mental health: experiences of psychosocial care centers for children and adolescents (CAPSIJ) in Brazil's Southeastern region

The study aimed to identify how intersectoral work has been produced in Psychosocial Care Centers for Children and Adolescents (CAPSij) in Brazil's southeast region, seeking to understand how the contacts with the network are processed, as well as the strengths and weaknesses of intersectoral articulations in the perspective of service managers. This study is a survey research, guided by the triangulation of methods for results analysis, which in the first stage regards the analysis for situational diagnostic; CAPSij participated. The results indicated that Primary Care, Social Assistance and Education are the main services/sectors involved in care situations for children and adolescents assisted by the CAPSij. Co-responsibility, as one of the benefits of intersectoral work, was asserted as a strategy for expanded health production and network qualification. On challenges, the participants point out the lack of alignment in common care projects, life medicalization and pathologization discourses in educational institutions, and the difficulty of articulating demands related to Primary Care. Finally, intersectoriality is discussed as the central axis in Mental Health actions, allowing local resources and devices to be strengthened for care practices and assurance of rights.

> Keywords: mental health; child; adolescent; intersectoriality. 